\title{
The effects of feeding rations that differ in neutral detergent fiber and starch within a day on the daily pattern of key rumen microbial populations
}

\author{
I. J. Salfer, ${ }^{1} \odot$ C. E. Crawford, ${ }^{2 *}$ L. W. Rottman, ${ }^{2} \dagger$ and K. J. Harvatine ${ }^{2} \neq \odot$
}

\section{Graphical Abstract}

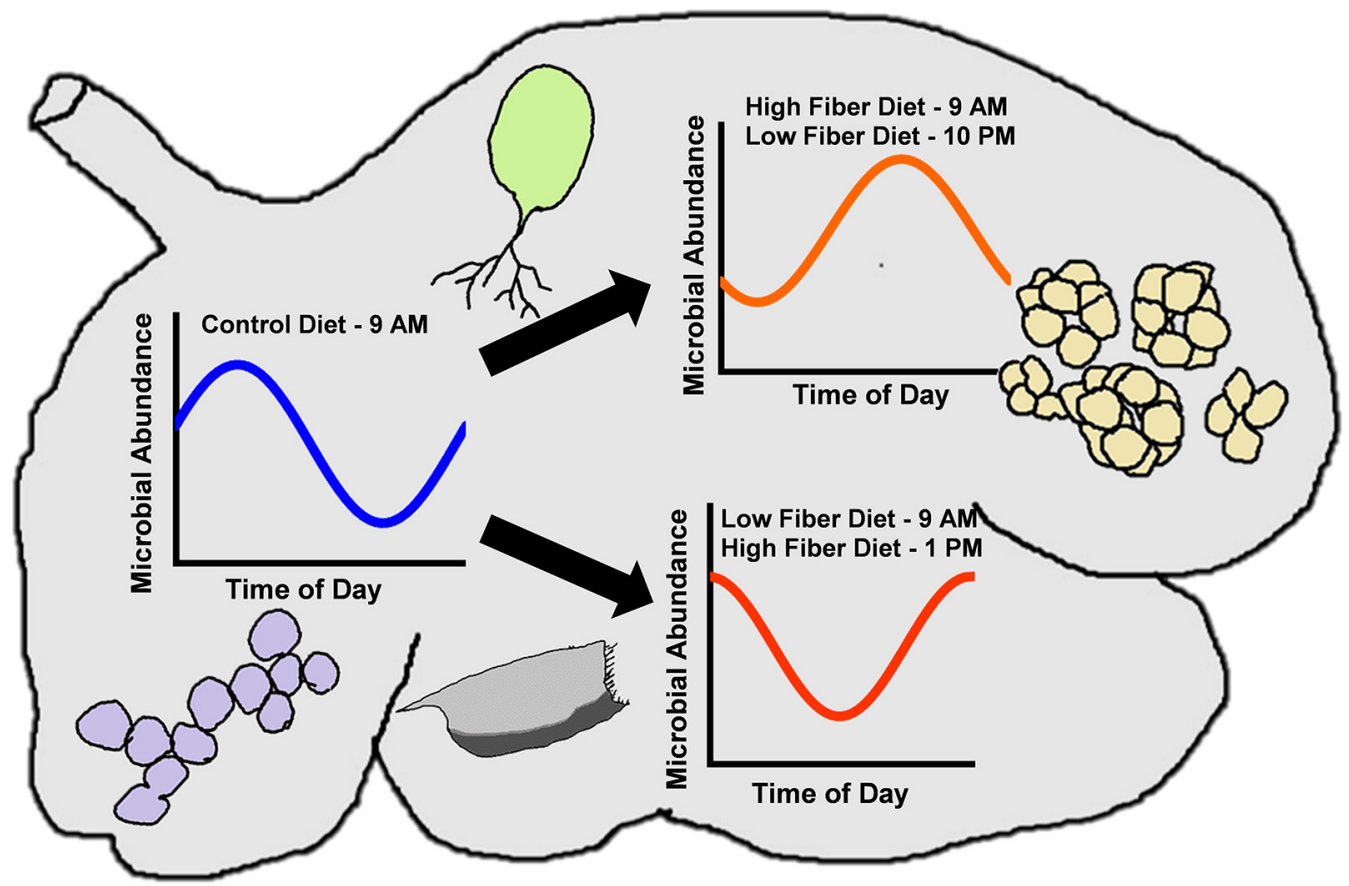

\section{Summary}

The timing of feeding of starch and fiber affects daily patterns of rumen $\mathrm{pH}$, nutrient digestion, and milk production but there is little information on the effect on daily patterns of rumen microbial populations. This study measured the relative abundance of rumen bacteria, protozoa, fungi and bacterial species in response to feeding diets that altered the concentration of fiber and starch to cows across the day. The results show that that relative abundance of microbial species is dynamic across the day and that their daily patterns are affected by the timing of feeding starch and fiber.

\section{Highlights}

- Rumen microbial relative abundance follows a daily pattern.

- Feeding 2 diets differing in starch and neutral detergent fiber (NDF) modifies microbial daily pattern.

- Streptococcus bovis and Butyrivibrio peaked before feeding of a high-NDF diet in the morning.

- Ruminococcus albus, Selenomonas ruminantium, and Fibrobacter succinogenes increased before feeding a low NDF diet.

\footnotetext{
${ }^{1}$ Department of Animal Science, University of Minnesota, St. Paul 55108, ${ }^{2}$ Department of Animal Science, The Pennsylvania State University, University Park 16802. * Current address: 1490 Tuskawilla Rd, Oviedo, FL 32765. +Current address: Novozymes Biologicals Inc., Salem, VA 24153. ¥Corresponding author: kjh182@psu.edu. @ 2021, The Authors. Published by Elsevier Inc. and Fass Inc. on behalf of the American Dairy Science Association ${ }^{\oplus}$. This is an open access article under the CC BY license (http://creativecommons.org/licenses/by/4.0/). Received February 24, 2021. Accepted July 19, 2021.
} 


\title{
The effects of feeding rations that differ in neutral detergent fiber and starch within a day on the daily pattern of key rumen microbial populations
}

\author{
I. J. Salfer, ${ }^{1} \odot$ C. E. Crawford, ${ }^{2 *}$ L. W. Rottman, ${ }^{2} \dagger$ and K. J. Harvatine ${ }^{2} \neq \odot$
}

Abstract: The effect of feeding a single TMR versus multiple rations across the day that differ in concentrations of neutral detergent fiber (NDF) and starch on the daily pattern of rumen microbial populations was characterized. Diets included a control total mixed ration (CON; 33.3\% NDF), a low-fiber diet (LF; 29.6\% NDF), and a high-fiber diet (HF; 34.8\% NDF). Nine cannulated Holstein cows were assigned to 1 of 3 treatment sequences in a $3 \times 3$ Latin square design. Treatments included feeding CON ad libitum at $0900 \mathrm{~h}$, feeding $\mathrm{HF}$ at $70 \%$ of daily offering at $0900 \mathrm{~h}$ and LF at $30 \%$ of daily offering at $2200 \mathrm{~h}(\mathrm{H} / \mathrm{L})$, and feeding LF at $30 \%$ of daily offering at 0900 $\mathrm{h}$ and $\mathrm{HF}$ at $70 \%$ of daily offering at $1300 \mathrm{~h}(\mathrm{~L} / \mathrm{H})$. Rumen digesta was collected to represent every $3 \mathrm{~h}$ across the day, microbial DNA was extracted, and real-time quantitative PCR was used to determine the relative abundances of total bacteria, total fungi, total protozoa, Butyrivibrio fibrisolvens, Butyrivibrio hungatei, Fibrobacter succinogenes, Megasphaera elsdenii, Prevotella bryantii, Ruminococcus albus, Selenomonas ruminantium, and Streptococcus bovis. The relative abundances of total bacteria, total ciliated protozoa, F. succinogenes, P. bryantii, R. albus, S. ruminantium, and Strep. bovis were affected by time of day. Additionally, treatment affected the relative abundance of certain microbial groups at specific times of day. Notably, H/L treatment dramatically increased the relative abundances of B. fibrisolvens, B. hungatei, and Strep. bovis at $0900 \mathrm{~h}$, by 2.5-, 5.4-, and 4.4-fold, respectively. Furthermore, the relative abundances of B. hungatei (3.9-fold), M. elsdenii (3.9-fold), R. albus (1.3-fold), S. ruminantium (1.3-fold), and Strep. bovis (4.5-fold) were greatly increased by $\mathrm{L} / \mathrm{H}$ at $0900 \mathrm{~h}$. At $0600 \mathrm{~h}$, the relative abundance of $F$. succinogenes was $58 \%$ greater in $\mathrm{L} / \mathrm{H}$ than $\mathrm{H} / \mathrm{L}$ and the relative abundance of $P$. bryantii was $49 \%$ greater in $\mathrm{H} / \mathrm{L}$ than $\mathrm{L} / \mathrm{H}$. Results suggest that there is a daily pattern of selected microbial populations that is altered by feeding rations that differ in NDF and starch within a day, with the greatest difference occurring before morning feeding.

C attle naturally exhibit a crepuscular pattern of feed intake and traditionally consume greater amounts of feed in the morning and evening (Albright, 1993). In dairy cows, milking and the delivery of fresh feed act as strong stimuli for intake, and periods of high intake occur after feed delivery and milking and during the afternoon and early evening (DeVries et al., 2003). Most dairy farms currently feed a TMR once or twice daily, which is expected to deliver a consistent concentration of nutrients per meal. However, because of cows' daily feeding patterns, there is a large change in the amount of feed entering the rumen across the day, with 3 to 8 times more fermentable substrate entering the rumen during high-intake periods (Ying et al., 2015). These observations stand in direct opposition to the assumption of a rumen steady state that is used in most nutritional models (Fox et al., 2004).

Further evidence of daily fermentation dynamics is provided by diurnal observations of rumen $\mathrm{pH}$. Rumen $\mathrm{pH}$ typically peaks just before feeding and declines to reach a nadir about $10 \mathrm{~h}$ later during the high intake period of the day (Yang and Beauchemin, 2006; Salfer et al., 2018). The daily pattern of rumen $\mathrm{pH}$ is opposite that of trans-10 C18:1 fatty acids in the rumen, which are associated with biohydrogenation-induced milk fat depression (Ying et al., 2015). We previously reported that the daily pattern of rumen $\mathrm{pH}$ was altered by feeding rations that differed in NDF and starch concentrations within a day (Ying et al., 2015). Moreover, total VFA, acetate, and propionate concentrations also follow a daily rhythm, with all reaching a nadir at approximately $0900 \mathrm{~h}$ (Ying et al., 2015). Rumen redox potential (Richter et al., 2010) and methane production follow daily rhythms that are responsive to feeding (Crompton et al., 2011; Zhou et al., 2011). Finally, total rumen volume and DM and NDF pool sizes are modified by diet and follow a daily rhythm, suggesting that rumen outflow also follows a daily rhythm (Gasa et al., 1991; Ying et al., 2015).

The daily patterns of nutrient intake, nutrient digestion, rumen $\mathrm{pH}$, and rumen turnover may cause - or be caused by - changes in rumen microbial abundance and composition across the day. Bryant and Robinson (1961) reported a daily pattern of bacterial abundance quantified as total bacterial colony counts in the rumen, and the pattern differed between grain- and hay-based diets. The abundance of bacteriophage also displays a cosine-shaped daily pattern with a peak about 8 to $10 \mathrm{~h}$ post-feeding (Klieve and Swain, 1993). Furthermore, apparent microbial protein synthesis follows a daily pattern in sheep, peaking approximately $8 \mathrm{~h}$ after feeding (Walker and Nader, 1970). Recent research has suggested that gut microbes of mice undergo daily oscillations and may be under the control of circadian rhythms (Liang and FitzGerald, 2017). Moreover, a molecular circadian mechanism has been established in cyanobacteria, demonstrating the possibility of true circadian rhythms in prokaryotes (Pattanayak and Rust, 2014). However, to our knowledge, no experiments have examined daily patterns of specific microbial species in dairy cows. 
We previously proposed that changing diet composition across the day could create a more stable rumen environment (Rottman et al., 2015). Briefly, feeding a higher NDF and lower starch diet during the high-intake period of the day and a lower NDF and higher starch diet during the lower-intake period during the night was expected to create a more consistent amount of starch entering the rumen. In contrast, feeding a low-NDF and high-starch diet first during the high-intake period of the day was designed to exacerbate changes across the day.

The objective of the current experiment was to examine the effect of feeding rations that differ in NDF and starch within a day on daily patterns of total rumen bacteria, protozoa, fungi, and bacterial species with well-defined niches within the rumen. We hypothesize that modifying the timing of fiber and starch feeding will shift the daily patterns of microbial relative abundance, such that fiber-utilizing species and anaerobic fungi will peak within $4 \mathrm{~h}$ of feeding the high-fiber diet and that starch-utilizing species will peak within $4 \mathrm{~h}$ of feeding the high-starch diet. Furthermore, the relative abundance of bacteria is expected to be stabilized when the high-fiber diet is fed in the morning due to the slower growth of fibrolytic bacterial species. The effects on feeding behavior, milk yield, FA profile, and plasma hormone and metabolite concentrations (Rottman et al., 2015) and daily changes in rumen digesta nutrient concentration and pool size including starch, NDF, and individual FA, rumen pH, and VFA (Ying et al., 2015) have been previously reported.

Experimental procedures were approved by the Penn State University Institutional Animal Care and Use Committee. Nine multiparous lactating Holstein cows $(158 \pm 48$ DIM, mean \pm SD) from the Pennsylvania State University Dairy Research and Teaching Center were randomly assigned to 1 of 3 treatment sequences in a $3 \times 3$ Latin square design with 23 -d periods $(n=9$ per sequence), as described by Rottman et al. (2015). Sample size was determined for the original experiment based on $>80 \%$ power of observing a $P<0.05$ difference in milk yield based on the variance observed in previous experiments. Randomization was conducted using the rand() function of Excel (Microsoft Corp.), generating random numbers corresponding to each stall and ranking the random numbers numerically to match stalls with treatment sequences. Treatment sequences were balanced to minimize carryover effects.

Cows were housed in tiestalls with a 19-h light phase and a 5-h dark phase from 0000 to $0500 \mathrm{~h}$. Cows were milked twice per day at 0700 and $1700 \mathrm{~h}$. Three rations were fed: a control complete TMR (CON; 33.1\% NDF), a low-fiber diet (LF; 29.6\% NDF), and a high-fiber diet (HF; 34.8\% NDF). Dietary NDF level was modified by substituting corn grain for forage. Diets were balanced so that a 7:3 ratio of HF:LF offered the same nutrient composition as the CON diet. Treatments included feeding CON at 0900 h, feeding $\mathrm{HF}$ at $70 \%$ of daily offering at $0900 \mathrm{~h}$ and LF at $30 \%$ of daily offering at $2200 \mathrm{~h}(\mathbf{H} / \mathbf{L})$, and feeding LF at $30 \%$ of daily offering at $0900 \mathrm{~h}$ and $\mathrm{HF}$ at $70 \%$ of daily offering at $1300 \mathrm{~h}(\mathbf{L} / \mathbf{H})$. All cows were fed at $110 \%$ of expected daily intake and orts were removed before feed delivery.

Rumen digesta were sampled every $9 \mathrm{~h}$ from d 15 to 17 of each period to represent every $3 \mathrm{~h}$ of the day $(0000,0300,0600,0900$, $1200,1500,1800$, and 2100 h). Manual grab samples of whole digesta were collected from 6 regions of the rumen (cranial dorsal, cranial ventral, central, caudal, dorsal, and caudal ventral). Digesta were composited, subsampled (approximately $250 \mathrm{~g}$ ), and stored at $-20^{\circ} \mathrm{C}$ before analysis. Samples were lyophilized (VirTis Ultra 35-XL, SP Industries) and ground using a consumer-grade coffee grinder (model 90 335; Hamilton Beach Brands Inc.) for 60 s. DNA was extracted using a commercially available extraction kit (E.Z.N.A. Stool DNA Kit; Omega Bio-Tek) with modifications similar to those in Yu and Morrison (2004), as described by Rico et al. (2015). Concentration and purity of DNA were determined by spectrophotometry at 260 and $280 \mathrm{~nm}$ (NanoDrop ND-1000, NanoDrop Technologies). All samples were diluted to $100 \mu \mathrm{g} / \mathrm{dL}$ before downstream analysis. The relative abundances of total bacteria, Butyrivibrio fibrisolvens, Butyrivibrio hungatei, Fibrobacter succinogenes, Megasphaera elsdenii, Prevotella bryantii, Prevotella ruminicola, Ruminococcus albus, Selenomonas ruminantium, and Streptococcus bovis were determined using real-time quantitative PCR (qPCR) with previously designed primers (Table 1) targeting the 16S rRNA gene according to Rico et al. (2015). Total anaerobic fungi and total ciliate protozoa were quantified by qPCR of the $18 \mathrm{~S}$ rRNA gene using primers described by Sylvester et al. (2004) and Denman and McSweeney (2006), respectively (Table 1). These organisms were chosen because of their established metabolic niches in the rumen. Quantification was performed using the relative standard curve method with an Applied Biosystems 7900HT Fast Real-Time PCR system (Applied Biosystems Inc.) and SYBR Green reporting dye (PerfeCTa Supermix with ROX, Quanta Biosciences). Primer specificity was evaluated using melting curve analysis, and primer efficiency $(E)$ was calculated from the standard curve as $E=10^{-1 / \text { slope }}$. Efficiency values ranged from 84 to $126 \%(98.0 \% \pm 2.1 \%$; mean \pm SEM). Relative abundance of bacteria, anaerobic fungi, and ciliate protozoa and individual bacterial species were calculated relative to a standard curve with 2-fold dilutions included in duplicate on each qPCR plate. Relative abundance of individual bacterial species was expressed as a percentage of total bacteria.

All data were analyzed as repeated measures using the MIXED procedure of SAS 9.4 (SAS Institute Inc.). The model included the fixed effects of treatment, time, and the interaction of treatment and time, as well as the random effects of cow, period, and qPCR plate to remove the effect of technical variation among plates $(\mathrm{n}=$ 3 cows/plate). Time was included as a repeated variable within the model. The autoregressive covariance structure was chosen over the heterogeneous structure based on Bayesian information criterion and convergence criteria, and denominator degrees of freedom were adjusted using the Kenward-Roger method. Preplanned contrasts were used to test differences between CON and H/L and between $\mathrm{H} / \mathrm{L}$ and $\mathrm{L} / \mathrm{H}$ at each time point. Statistical significance was declared at $P<0.05$ and trends noted at $0.05<P<0.10$. Heteroscedasticity was determined by generating a histogram and normal Q-Q plot of residuals in PROC MIXED. High-resolution figures were generated using an add-in for Microsoft Excel (Kraus, 2014).

In a previously published paper, we observed that both $\mathrm{H} / \mathrm{L}$ and $\mathrm{L} / \mathrm{H}$ decreased total DMI relative to $\mathrm{CON}$, which coincided with a decrease in feeding time (Rottman et al., 2015). Moreover, milk and milk fat yields were greater for $\mathrm{H} / \mathrm{L}$ than $\mathrm{L} / \mathrm{H}$. Additionally, the eating rate post-feeding was increased in $\mathrm{L} / \mathrm{H}$ relative to $\mathrm{H} / \mathrm{L}$, 
which was associated with increased rumen $\mathrm{pH}$, propionate concentrations, and concentrations of trans-10 C18:1 before feeding (Ying et al., 2015).

In the current analysis, the relative abundance of total bacteria was affected by time of day, suggesting a daily pattern $(P=0.005$; Figure 1A). Bacterial abundance was greatest in the morning, similar to previous results by Bryant and Robinson (1961). Neither average bacterial abundance $(P=0.80)$ nor the daily pattern $(P=$ $0.69)$ was affected by treatment. The relative abundance of ciliate protozoa was similarly affected by time of day $(P<0.0001)$ but not treatment $(P=0.26)$, nor was there a treatment by time interaction $(P=0.26$; Figure 1B). Ciliate protozoa abundance peaked at 0600 $\mathrm{h}$ in $\mathrm{L} / \mathrm{H}$, at $0900 \mathrm{~h}$ in $\mathrm{CON}$, and at $1200 \mathrm{~h}$ in $\mathrm{H} / \mathrm{L}$. Our results coincide with those observed by Michalowski and Muszyński (1978), who similarly detected variation in protozoal abundance across the day, with maximum abundance occurring immediately before feeding. Based on our results, it appears that the time of starch feeding is more closely associated with increasing protozoal abundance, which agrees with previous research suggesting that starch is a more potent stimulus of protozoal growth than fiber (Ishaq et al., 2017). Although protozoal reproduction is generally slower than bacterial cell division, certain species of Entodinium protozoa can replicate within $15 \mathrm{~min}$, allowing for changes in the population throughout the day (Williams and Coleman, 1997). Notably, protozoa undergo chemotaxis toward areas of the rumen with greater nutrient density (Firkins et al., 2020). Even though we analyzed composite samples from all regions of the rumen, the observed differences in protozoal numbers might be partly due to migration of protozoa to different regions of the rumen.

The abundance of anaerobic fungi was not affected by treatment $(P=0.99)$ or time of day $(P=0.57)$, and there was no interaction of treatment and time of day $(P=0.35$; Figure $1 C)$. Results disagree with previous data that suggested a large increase in population density of fungi $1 \mathrm{~h}$ after feeding; however, those results were obtained using culture-based techniques, which may be biased by the cultivability of fungi species (Orpin and Joblin, 1997). Moreover, our results included total rumen contents, including fungal cells attached to plant cell walls within the solids phase of the rumen, which may have resulted in a more complete measurement of their populations. Rumen fungi have been purported to replicate only 2 to 4 times per day and, therefore, would have limited ability to change their population density greatly throughout a day (Orpin, 1975).

Fibrobacter succinogenes and R. albus are 2 of the best characterized cellulose-degrading bacterial species present in the rumen. Relative abundance of $F$. succinogenes differed across the day $(P<0.0001)$ but was not affected by treatment $(P=0.14)$ or the interaction of treatment and time $(P=0.74$; Figure $2 \mathrm{C})$. However, analysis at the $0600 \mathrm{~h}$ time point showed an increase in $\mathrm{F}$. succinogenes under the $\mathrm{L} / \mathrm{H}$ feeding schedule relative to $\mathrm{H} / \mathrm{L}$ and a tendency for an increase relative to $\mathrm{CON}$. One potential reason for the high relative abundance of $F$. succinogenes bacteria before feeding is the slow rate of fiber fermentation, which may lead to these organisms remaining in the rumen to continue to digest fiber, whereas more rapidly degraded nutrients like starch and amino acids may have been depleted at this time. The relative abundance of $R$. albus was affected by time $(P<0.0001)$ and there tended to be a treatment by time interaction $(P=0.09$; Figure $2 \mathrm{~F})$. At the $0900 \mathrm{~h}$ time point, $\mathrm{L} / \mathrm{H}$ increased $R$. albus abundance $(P=0.01)$, whereas $\mathrm{H} / \mathrm{L}$ tended to decrease its abundance $(P=0.08)$. These results contradict our hypothesis that fiber-degrading bacterial species would be elevated after the high-fiber diet was fed, and instead suggest that growth of these species occurs closer to the time of feeding a high-starch, low-fiber diet. This outcome may be due to interrelationships with other microbial species or may be due to a several-hour delay in growth after feeding the high-fiber diet.

Table 1. List of primers used to quantify microbial groups using quantitative real-time PCR

\begin{tabular}{|c|c|c|c|}
\hline Organism & Primer (top: forward; bottom: reverse) ${ }^{1}$ & $\mathrm{~T}_{\mathrm{a}}^{2}$ & Reference \\
\hline Bacteria & $\begin{array}{l}\text { CGGCAACGAGCGCAACCC } \\
\text { CCATTGTAGCACGTGTGTAGCC }\end{array}$ & 60 & Denman and McSweeney (2006) \\
\hline Ciliate protozoa & $\begin{array}{l}\text { GCTTTCGWTGGTAGTGTATT } \\
\text { CTTGCCCTCYAATCGTWCT }\end{array}$ & 55 & Sylvester et al. (2004) \\
\hline Fungi & $\begin{array}{l}\text { GAGGAAGTAAAAGTCGTAACAAGGTTTC } \\
\text { CAAATTCACAAAGGGTAGGATGATT }\end{array}$ & 60 & Denman and McSweeney (2006) \\
\hline Butyrivibrio fibrisolvens & $\begin{array}{l}\text { GCCTCAGCGTCAGTAATCG } \\
\text { GGAGCGTAGGCGGTTTTAC }\end{array}$ & 65 & Shingfield et al. (2012) \\
\hline Fibrobacter succinogenes & $\begin{array}{l}\text { GCGGGTAGCAAACAGGATTAGA } \\
\text { CCCCCGGACACCCAGTAT }\end{array}$ & 60 & Stevenson and Weimer (2007) \\
\hline Megasphaera elsdenii & $\begin{array}{l}\text { GACCGAAACTGCGATGCTAGA } \\
\text { CGCCTCAGCGTCAGTTGTC }\end{array}$ & 60 & Ouwerkerk et al. (2002) \\
\hline Prevotella bryantii & $\begin{array}{l}\text { AGCGCAGGCCGTTTGG } \\
\text { GCTTCCTGTGCACTCAAGTCTGAC }\end{array}$ & 61 & Stevenson and Weimer (2007) \\
\hline Ruminococcus albus & $\begin{array}{l}\text { CCCTAAAAGCAGTCTTAGTTCG } \\
\text { CCTCCTTGCGGTTAGAACA }\end{array}$ & 61 & Wang et al. (1997) \\
\hline
\end{tabular}

\footnotetext{
${ }^{1}$ Selected forward and reverse primers for validated for genes encoding 165 ribosomal RNA (bacterial species and fungi), and for the $18 \mathrm{~S}$ rRNA gene (protozoa). ${ }^{2} \mathrm{~T}_{\mathrm{a}}=$ annealing temperature $\left({ }^{\circ} \mathrm{C}\right)$.
} 
A
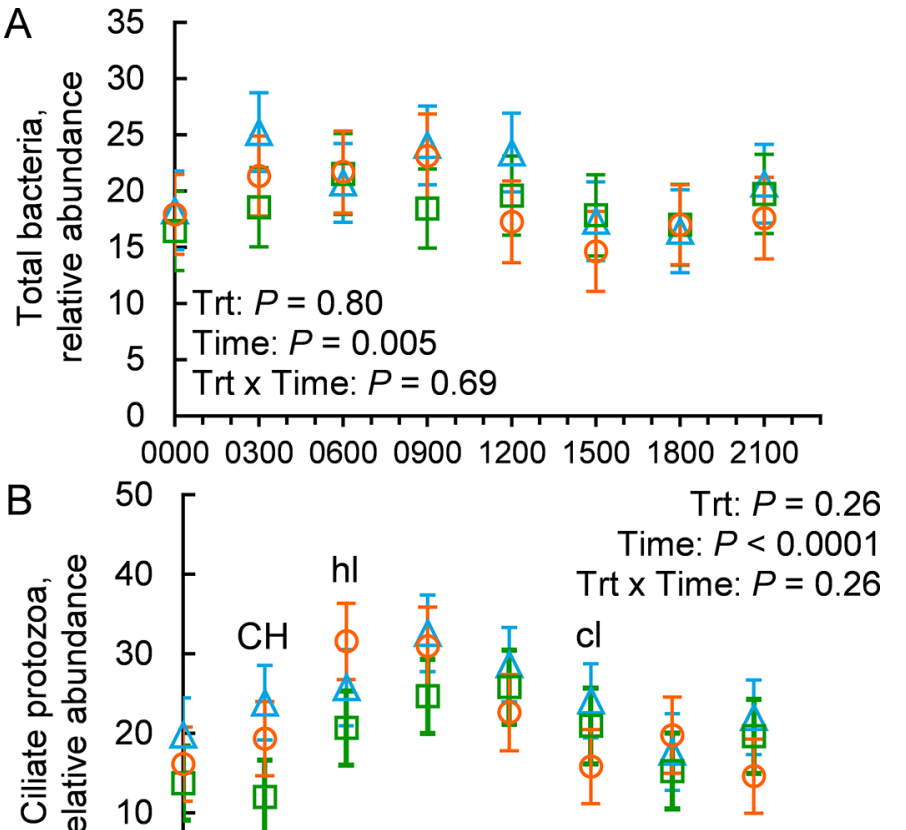

Butyrivibrio fibrisolvens, which utilizes a diversity of structural and nonstructural carbohydrates, including cellulose and hemicellulose, was not affected by treatment $(P=0.29)$, time $(P=0.20)$, or their interaction $(P=0.29)$. However, when the $0900 \mathrm{~h}$ data were examined independently, $\mathrm{H} / \mathrm{L}$ increased $B$. fibrisolvens abundance compared with $\mathrm{CON}(P=0.0001)$ and $\mathrm{L} / \mathrm{H}(P=0.002$; Figure $2 \mathrm{~A})$.

Notable nonstructural carbohydrate-degrading bacteria in the rumen include Strep. bovis, S. ruminantium, and P. bryantii (Russell, 2002). Streptococcus bovis, a rapid degrader of starch and a major producer of ruminal lactate, was affected by time $(P=0.02)$ but not treatment, and there was no treatment by time interaction (Figure $2 \mathrm{H})$. At the $0900 \mathrm{~h}$ time point, the abundance of Strep. bovis was increased $\sim 200 \%$ by both $\mathrm{H} / \mathrm{L}(P=0.04)$ and $\mathrm{L} / \mathrm{H}(P=0.03)$, suggesting that compared with feeding a single TMR, feeding 2 diets that differ in starch and fiber concentration cause a dramatic increase in Strep. bovis during initial feeding time, regardless of the timing of the 2 diets. Selenomonas ruminantium, which can utilize oligosaccharides, glucose, and lactate as substrates, also differed across the day $(P=0.005)$ but was not affected by treatment or the interaction of treatment and time (Cotta and Whitehead, 1998; Figure 2G). However, at the $0900 \mathrm{~h}$ time point, the $\mathrm{L} / \mathrm{H}$ treatment increased abundance of $S$. ruminantium relative to $\mathrm{CON}$ and $\mathrm{H} / \mathrm{L}$ $(P=0.01)$ and tended to increase its relative abundance at the 1200 h time point $(P=0.07)$. Moreover, $\mathrm{H} / \mathrm{L}$ decreased $S$. ruminantium relative to $\mathrm{CON}$ at $0300 \mathrm{~h}(P=0.05)$. Results suggest that $S$. ruminantium growth is stimulated within the first $6 \mathrm{~h}$ after feeding a high-starch diet, coinciding with its primary niche as a fermenter of nonstructural carbohydrates. The relative abundance of $P$. bryantii tended to be altered by treatment $(P=0.08)$ and was affected by time $(P<0.0001)$ but was not affected by the interaction of treatment and time $(P=0.45$; Figure $2 \mathrm{E})$. At $0600 \mathrm{~h}, \mathrm{H} / \mathrm{L}$ increased $P$. bryantii relative to $\mathrm{L} / \mathrm{H}(P=0.04)$ and tended to increase $P$. bryantii relative to $\mathrm{CON}(P=0.45)$.

Megasphaera elsdenii and B. hungatei are 2 species that are important utilizers of rumen lactate and play a role in biohydrogenation of fatty acids. Neither treatment, time of day, or their interaction affected the relative abundance of Megasphaera elsdenii (Figure 2D). However, when the $0900 \mathrm{~h}$ time point was investigated independently, $\mathrm{L} / \mathrm{H}$ increased abundance of $M$. elsdenii compared with $\mathrm{CON}(P=0.01)$ and $\mathrm{H} / \mathrm{L}(P=0.02)$. The $\mathrm{L} / \mathrm{H}$ treatment also tended to increase $M$. elsdenii relative abundance compared with $\mathrm{H} / \mathrm{L}$ at the $2100 \mathrm{~h}$ time point $(P=0.05)$. Similarly, the relative abundance of $B$. hungatei was not affected by treatment $(P=0.61)$, time $(P=0.14)$, or the interaction of treatment and time $(P=0.90$; Figure 2B). Specifically at $0900 \mathrm{~h}, \mathrm{H} / \mathrm{L}$ increased $(P=0.005)$ and $\mathrm{L} / \mathrm{H}$ tended to increase $(P=0.07) B$. hungatei relative abundance compared with CON.

Overall, the results of this experiment demonstrate that the abundance of microbial species is dynamic across the day and that their daily patterns are affected by the timing of feeding starch and fiber. Most notably, 2 species that rapidly ferment nonstructural carbohydrates, Strep. bovis and B. hungatei, rapidly increased during the first $3 \mathrm{~h}$ after the first daily feeding when the 2 diets differing in starch and fiber were fed, regardless of the order in which the 2 diets were fed. This may indicate that feeding rations that differ in composition over the day modifies microbial responsiveness and increases dynamic responses to feeding. Contrary to our hy- 

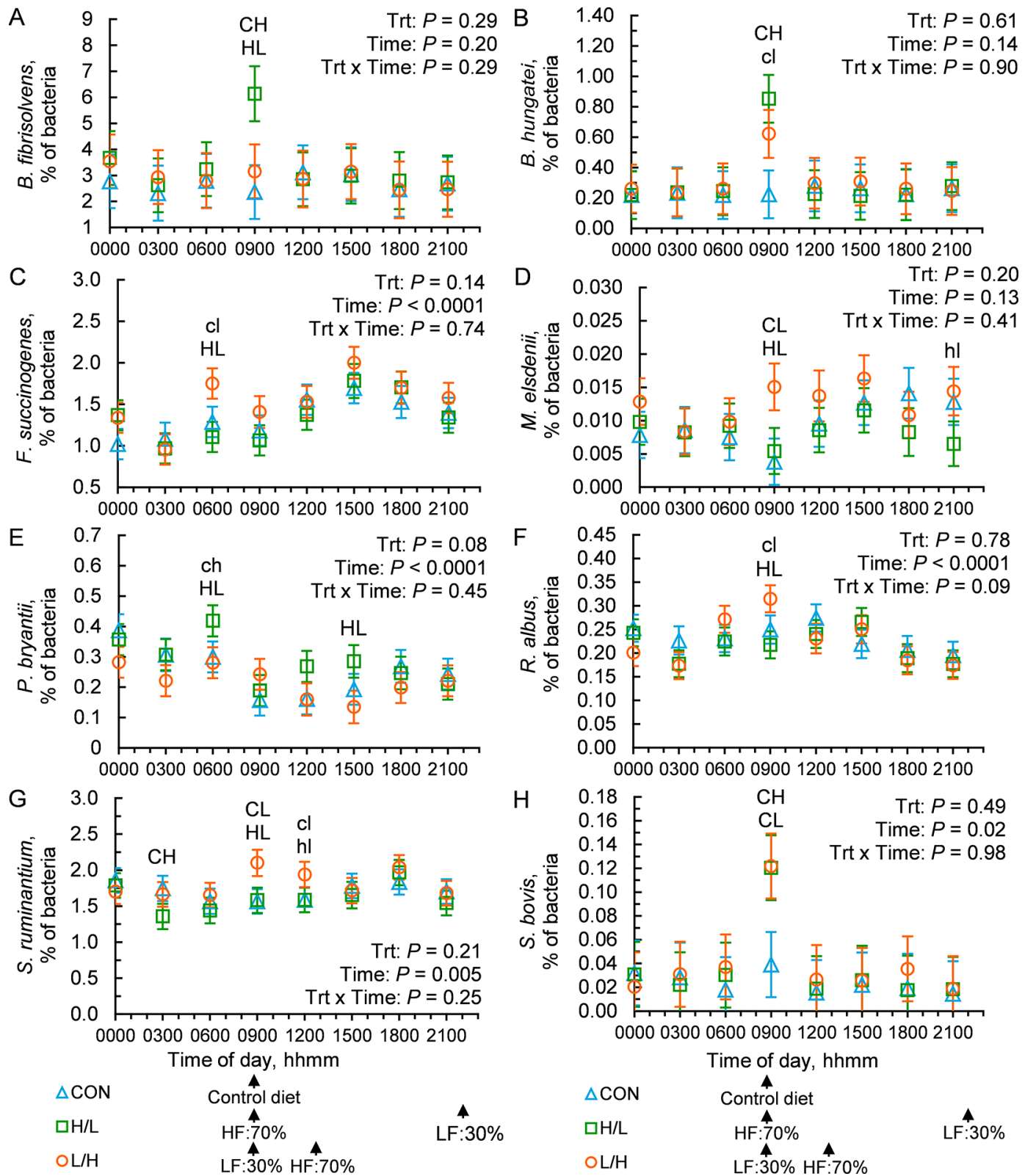

Figure 2. Effects of feeding rations that differ in NDF and starch within a day on relative abundances of prominent bacterial species in the rumen across the day. Bacterial species include (A) Butyrivibrio fibrisolvens, (B) Butyrivibrio hungatei, (C) Fibrobacter succinogenes, (D) Megasphaera elsdenii, (E) Prevotella bryantii, (F) Ruminococcus albus, (G) Selenomonas ruminantium, (H) Streptococcus bovis. Rations included a control complete TMR (33.1\% NDF), a low-fiber diet (LF; $29.6 \% \mathrm{NDF}$ ), and a high-fiber diet (HF; $34.8 \% \mathrm{NDF})$. Treatments included feeding the control diet at $0900 \mathrm{~h}(\mathrm{CON})$, feeding HF at $70 \%$ of daily offering at $0900 \mathrm{~h}$ and LF at $30 \%$ of daily offering at $2200 \mathrm{~h}(\mathrm{H} / \mathrm{L})$, and feeding the $\mathrm{LF}$ at $30 \%$ of daily offering at $0900 \mathrm{~h}$ and $\mathrm{HF}$ at $70 \%$ of daily offering at $1300 \mathrm{~h}(\mathrm{~L} / \mathrm{H})$. Treatment means with SEM bars and the effects of treatment (Trt), time, and their interaction are shown. Preplanned contrasts were used to test difference between $\mathrm{CON}$ and $\mathrm{H} / \mathrm{L}$ and between $\mathrm{H} / \mathrm{L}$ and $\mathrm{L} / \mathrm{H}$ at each time point. Differences at individual time points are presented as letters: $\mathrm{C}, \mathrm{H}$, and $\mathrm{L}$ denote $\mathrm{CON}, \mathrm{H} / \mathrm{L}$, and $\mathrm{L} / \mathrm{H}$, respectively. Uppercase letters above time points indicate differences between denoted treatments $(P<0.05)$, and lowercase letters above time points indicate a tendency for difference between denoted treatments $(0.05 \leq P<0.10)$.

pothesis, the dynamics of individual microbial species abundance did not directly correspond to intake of nutrients that are known substrates for their growth, with prominent fiber-degrading bacteria increasing after high-starch diets were fed. It is likely that more complex dynamics were related to cross-feeding. Moreover, many of the microbial species examined may have niches beyond their traditionally assumed roles in the rumen. Future experiments with a broader scope, focusing on the complete rumen microbiome and metabolome, would provide additional insights into the daily patterns of rumen microbes and their relationship to nutrient intake. 


\section{References}

Albright, J. L. 1993. Feeding behavior of dairy cattle. J. Dairy Sci. 76:485-498. https://doi.org/10.3168/jds.S0022-0302(93)77369-5.

Bryant, M. P., and I. M. Robinson. 1961. An improved nonselective culture medium for ruminal bacteria and its use in determining diurnal variation in numbers of bacteria in the rumen. J. Dairy Sci. 44:1446-1456. https://doi .org/10.3168/jds.S0022-0302(61)89906-2.

Cotta, M. A., and T. R. Whitehead. 1998. Xylooligosaccharide utilization by the ruminal anaerobic bacterium Selenomonas ruminantium. Curr. Microbiol. 36:183-189. https://doi.org/10.1007/s002849900291.

Crompton, L. A., J. A. N. Mills, C. K. Reynolds, and J. France. 2011. Fluctuations in methane emission in response to feeding pattern in lactating dairy cows. Wageningen Academic Publishers.

Denman, S. E., and C. S. McSweeney. 2006. Development of a real-time PCR assay for monitoring anaerobic fungal and cellulolytic bacterial populations within the rumen. FEMS Microbiol. Ecol. 58:572-582. https://doi .org/10.1111/j.1574-6941.2006.00190.x.

DeVries, T. J., M. A. G. von Keyserlingk, and K. A. Beauchemin. 2003. Short communication: Diurnal feeding pattern of lactating dairy cows. J. Dairy Sci. 86:4079-4082. https://doi.org/10.3168/jds.S0022-0302(03)74020-X.

Firkins, J. L., Z. Yu, T. Park, and J. E. Plank. 2020. Extending Burk Dehority's perspectives on the role of ciliate protozoa in the rumen. Front. Microbiol. 11:123. https://doi.org/10.3389/fmicb.2020.00123.

Fox, D. G., L. O. Tedeschi, T. P. Tylutki, J. B. Russell, M. E. Van Amburgh, L. E. Chase, A. N. Pell, and T. R. Overton. 2004. The Cornell Net Carbohydrate and Protein System model for evaluating herd nutrition and nutrient excretion. Anim. Feed Sci. Technol. 112:29-78. https://doi.org/10.1016/j .anifeedsci.2003.10.006.

Gasa, J., K. Holtenius, J. D. Sutton, M. S. Dhanoa, and D. J. Napper. 1991. Rumen fill and digesta kinetics in lactating Friesian cows given two levels of concentrates with two types of grass silage ad lib. Br. J. Nutr. 66:381-398. https://doi.org/10.1079/BJN19910042.

Ishaq, S. L., O. AlZahal, N. Walker, and B. McBride. 2017. An investigation into rumen fungal and protozoal diversity in three rumen fractions, during high-fiber or grain-induced sub-acute ruminal acidosis conditions, with or without active dry yeast supplementation. Front. Microbiol. 8:1943. https:/ /doi.org/10.3389/fmicb.2017.01943.

Klieve, A. V., and R. A. Swain. 1993. Estimation of ruminal bacteriophage numbers by pulsed-field gel electrophoresis and laser densitometry. Appl. Environ. Microbiol. 59:2299-2303. https://doi.org/10.1128/aem.59.7.2299 $-2303.1993$.

Kraus, D. 2014. Consolidated data analysis and presentation using an opensource add-in for the Microsoft Excel ${ }^{\circledR}$ spreadsheet software. Med. Writ. 23:25-28. https://doi.org/10.1179/2047480613Z.000000000181.

Liang, X., and G. A. FitzGerald. 2017. Timing the microbes: The circadian rhythm of the gut microbiome. J. Biol. Rhythms 32:505-515. https://doi .org/10.1177/0748730417729066.

Michalowski, T., and P. Muszyński. 1978. Diurnal variations in number of ciliate protozoa in the rumen of sheep fed once and twice daily. J. Agric. Sci. 90:1-5. https://doi.org/10.1017/S0021859600048528.

Orpin, C. G. 1975. Studies on the rumen flagellate Neocallimastix frontalis. J. Gen. Microbiol. 91:249-262. https://doi.org/10.1099/00221287-91-2-249.

Orpin, C. G., and K. N. Joblin. 1997. The Rumen Anaerobic Fungi. Springer.

Ouwerkerk, D., A. V. Klieve, and R. J. Forster. 2002. Enumeration of Megasphaera elsdenii in rumen contents by real-time Taq nuclease assay. J. Appl. Microbiol. 92:753-758. https://doi.org/10.1046/j.1365-2672.2002 $.01580 . \mathrm{x}$.

Pattanayak, G., and M. J. Rust. 2014. The cyanobacterial clock and metabolism. Curr. Opin. Microbiol. 18:90-95. https://doi.org/10.1016/j.mib.2014 .02 .010 .

Richter, M., L. Křŕžová, and J. Třináctý. 2010. The effect of individuality of animal on diurnal pattern of $\mathrm{pH}$ and redox potential in the rumen of dry cows. Czech J. Anim. Sci. 55:401-407. https://doi.org/10.17221/1695 -CJAS.

Rico, D. E., S. H. Preston, J. M. Risser, and K. J. Harvatine. 2015. Rapid changes in key ruminal microbial populations during the induction of and recovery from diet-induced milk fat depression in dairy cows. Br. J. Nutr. 114:358-367. https://doi.org/10.1017/S0007114515001865.

Rottman, L. W., Y. Ying, K. Zhou, P. Bartell, and K. J. Harvatine. 2015. The effects of feeding rations that differ in neutral detergent fiber and starch concentration within a day on production, feeding behavior, total-tract digestibility, and plasma metabolites and hormones in dairy cows. J. Dairy Sci. 98:4673-4684. https://doi.org/10.3168/jds.2014-8859.

Russell, J. B. 2002. Rumen Microbiology and Its Role in Ruminant Nutrition. 1st ed. Cornell University.

Salfer, I. J., M. C. Morelli, Y. Ying, M. S. Allen, and K. J. Harvatine. 2018. The effects of source and concentration of dietary fiber, starch, and fatty acids on the daily patterns of feed intake, rumination, and rumen $\mathrm{pH}$ in dairy cows. J. Dairy Sci. 101:10911-10921. https://doi.org/10.3168/jds .2018-15071.

Shingfield, K. J., P. Kairenius, A. Ärölä, D. Paillard, S. Muetzel, S. Ahvenjärvi, A. Vanhatalo, P. Huhtanen, V. Toivonen, J. M. Griinari, and R. J. Wallace. 2012. Dietary fish oil supplements modify ruminal biohydrogenation, alter the flow of fatty acids at the omasum, and induce changes in the ruminal butyrivibrio population in lactating cows. J. Nutr. 142:1437-1448. https:// doi.org/10.3945/jn.112.158576.

Stevenson, D. M., and P. J. Weimer. 2007. Dominance of Prevotella and low abundance of classical ruminal bacterial species in the bovine rumen revealed by relative quantification real-time PCR. Appl. Microbiol. Biotechnol. 75:165-174. https://doi.org/10.1007/s00253-006-0802-y.

Sylvester, J. T., S. K. R. Karnati, Z. Yu, M. Morrison, and J. L. Firkins. 2004. Development of an assay to quantify rumen ciliate protozoal biomass in cows using real-time PCR. J. Nutr. 134:3378-3384. https://doi.org/10 $.1093 / \mathrm{jn} / 134.12 .3378$.

Walker, D., and C. Nader. 1970. Rumen microbial protein synthesis in relation to energy supply: Diurnal variation with once-daily feeding. Aust. J. Agric. Res. 21:747. https://doi.org/10.1071/AR9700747.

Wang, R. F., W. W. Cao, and C. E. Cerniglia. 1997. PCR detection of Ruminococcus spp. in human and animal faecal samples. Mol. Cell. Probes 11:259-265. https://doi.org/10.1006/mcpr.1997.0111.

Williams, A. G., and G. S. Coleman. 1997. The Rumen Protozoa. P. N. Hobson and C.S. Stewart, ed. Springer.

Yang, W. Z., and K. A. Beauchemin. 2006. Effects of physically effective fiber on chewing activity and ruminal $\mathrm{pH}$ of dairy cows fed diets based on barley silage. J. Dairy Sci. 89:217-228. https://doi.org/10.3168/jds.S0022 $-0302(06) 72086-0$

Ying, Y., L. W. Rottman, C. Crawford, P. A. Bartell, and K. J. Harvatine. 2015. The effects of feeding rations that differ in neutral detergent fiber and starch concentration within a day on rumen digesta nutrient concentration, $\mathrm{pH}$, and fermentation products in dairy cows. J. Dairy Sci. 98:4685-4697. https://doi.org/10.3168/jds.2014-8873.

Yu, Z., and M. Morrison. 2004. Comparisons of different hypervariable regions of rrs genes for use in fingerprinting of microbial communities by PCR-denaturing gradient gel electrophoresis. Appl. Environ. Microbiol. 70:4800-4806. https://doi.org/10.1128/AEM.70.8.4800-4806.2004.

Zhou, Y. Y., H. L. Mao, F. Jiang, J. K. Wang, J. X. Liu, and C. S. McSweeney. 2011. Inhibition of rumen methanogenesis by tea saponins with reference to fermentation pattern and microbial communities in $\mathrm{Hu}$ sheep. Anim. Feed Sci. Technol. 166-167:93-100. https://doi.org/10.1016/j.anifeedsci .2011.04.007.

\section{Notes}

\section{J. Salfer $\odot$ https://orcid.org/0000-0001-5895-8172}

K. J. Harvatine $\odot$ https://orcid.org/0000-0001-6422-2647

This research was supported in part by USDA Special Grant 2009-34281-20116 [principal investigator Harvatine], Agriculture and Food Research Initiative Competitive Grant No. 2015-67015-23358 from the USDA National Institute of Food and Agriculture (Kansas City, MO), and Penn State University, including USDA National Institute of Food and Agriculture Federal Appropriations under Project number PEN04664 and accession number 1017181.

The authors thank the Penn State Dairy Barn staff, as well as Rebecca Bomberger, Elaine Barnoff, Michel Baldin, Natalie Urrutia, Daniel Rico, Mutian Niu, Andrew Clarke, Grace Takacs, Ryan Fairbairn, Kaitlyn Proschold, and Megan Deeds (Penn State University, University Park, PA) for technical assistance.

The authors have not stated any conflicts of interest. 